Faculty of Science

Faculty Publications

This is a post-print version of the following article:

Organic-inorganic hybrid pigments from flavylium cations and palygorskite Gustavo Thalmer M. Silva, Cassio P. Silva, Marcelo H. Gehlen, Jessy Oake, Cornelia Bohne, \& Frank H. Quina

July 2018

The final publication is available via ScienceDirect at:

https://doi.org/10.1016/j.clay.2018.07.002

Citation for this paper:

Silva, G. T. M., Silva, C. P., Gehlen, M. H., Oake, J., Bohne, C., \& Quina F. H. (2018). Organic/inorganic hybrid pigments from flavylium cations and plygorskite. Applied Clay Science, 162, 478-486. https://doi.org/10.1016/j.clay.2018.07.002. 
$3 \quad$ Organic/inorganic hybrid pigments from flavylium cations

4

5

6

7

8 Gustavo Thalmer M. Silva, ${ }^{1}$ Cassio P. Silva, ${ }^{1}$ Marcelo H. Gehlen, ${ }^{2}$ Jessy

9

10

11

12

13

14

\section{and palygorskite}

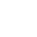

6

Oake, ${ }^{3}$ Cornelia Bohne, ${ }^{3}$ and Frank H. Quina*,1

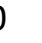

1

${ }^{1}$ Instituto de Química, Universidade de São Paulo, Av. Lineu Prestes 748, Cidade Universitária, São Paulo 05508-000, Brazil

${ }^{2}$ Instituto de Química de São Carlos, Universidade de São Paulo, 13566-590 São Carlos, 5 SP, Brazil
${ }^{3}$ Department of Chemistry and Centre for Advanced Materials and Related
Technologies (CAMTEC), University of Victoria, PO Box 1700 STN CSC, Victoria,
BC, Canada, V8W 2Y2

9

20

* Corresponding author.

E-mail address: quina@usp.br 


\section{Abstract}

Features such as color, brightness and fluorescence are extremely important in applications of pigments. Hybrid materials inspired by the ancient Maya Blue pigment are a promising alternative to improve the properties and applicability of natural and synthetic dyes. In this work, we report the preparation, photophysical properties, and stability of several fluorescent hybrid pigments based on flavylium cations (FL) adsorbed on palygorskite (PAL). Five flavylium cations were investigated, viz., the 3',4',7trimethoxyflavylium (FL1), 7-hydroxy-4'-methoxy-flavylium (FL2), 7-hydroxy-4methylflavylium (FL3), 5,7-dihydroxy-4-methylflavylium (FL4) and 7-methoxy-4methylflavylium (FL5) cations. Only FL1 and FL2, without a methyl substituent at the 4position that could hinder inclusion in palygorskite channels, adsorbed strongly on PAL, producing fluorescent hybrid pigments with attractive colors. The spectroscopic and fluorescence properties of the FL1/PAL and FL2/PAL hybrid pigments were characterized. The color of the adsorbed dyes was somewhat more resistant to changes in external $\mathrm{pH}$, photochemical stability was maintained and the thermal lability was markedly improved in the FL/PAL hybrid pigments, pointing to flavylium cations as promising chromophores for the development of fluorescent hybrid pigments with attractive colors.

Keywords: fluorescent hybrid pigments; palygorskite; dyes; clays; flavylium cations; color. 


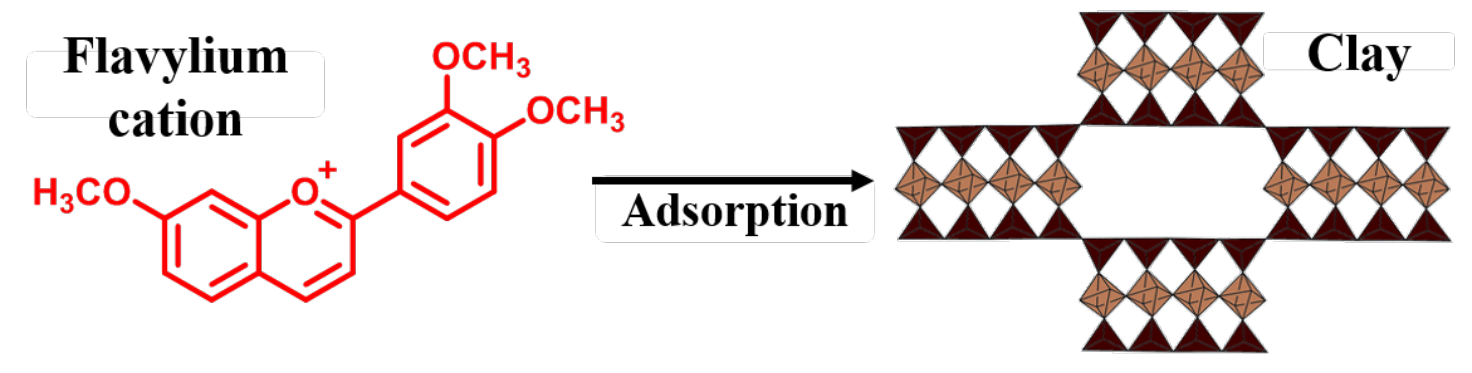

52

Flavylium cation

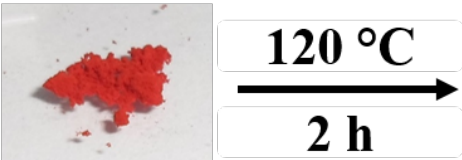

Hybrid pigment

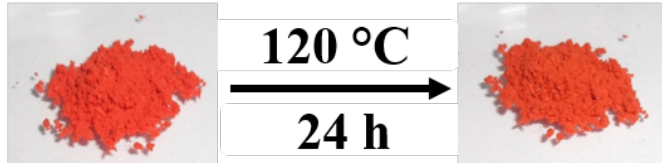




\section{Introduction}

(20)

Hybrid materials prepared by the combination of dyes with inorganic substrates have been extensively studied in search of materials with unique properties and color attributes (preferably bright and/or fluorescent) that are chemically, thermally and light stable (Laguna et al., 2007; Teixeira-Neto et al., 2009, 2012; Dejoie et al., 2010; Giustetto et al., 2014; Lin et al., 2014). One of the oldest and perhaps the most famous example of an organic-inorganic hybrid material is the Maya Blue pigment, which was widely used in murals, codices, ceramics and sculptures by the Maya civilization in the Pre-Columbian era. Maya Blue is extremely stable, able to resist the attack of concentrated nitric acid, bases and organic solvents without losing its color (Sánchez Del Río and Martinetto, 2006; Arnold and Branden, 2008; Chiari et al., 2008; Giustetto et al., 2011). The amazing chemical and photochemical stability of Maya Blue is presumably due to its unique structure, which consists of the dye indigo protectively (and apparently irreversibly) inserted into the channels of palygorskite or sepiolite clay (Giustetto et al., 2005, 2006, 2011; Chiari et al., 2008; Tilocca and Fois, 2009).

Palygorskite (PAL) is a hydrated magnesium and aluminum phyllosilicate clay mineral. Unlike most clays, PAL has fibrous morphology, consisting of a layer structure of ribbons of tetrahedral silica and central magnesium octahedra oriented along the fibers. The octahedral sheet is sandwiched between two tetrahedral sheets that have periodic inversion of the apical oxygen, resulting in well-defined one-dimensional cavities or tunnels (Sánchez Del Río et al., 2009; Doménech et al., 2011) with dimensions 3.7 x 6.4 $\AA$ (Brigatti et al., 2006) and, on the external surface of the clay fibers, partially open grooves or channels (as denominated for sepiolite by, e.g., Ruiz-Hitzky (2001) and Martínez-Martínez et al. (2011)). Several studies have shown that palygorskite has two 
main types of acidic sites, a sites of stronger acidity with an effective $\mathrm{pK}_{\mathrm{a}}$ in the range of 5-5.5 and more weakly acidic sites with a $\mathrm{pK}_{\mathrm{a}}$ around 9-9.5 (Frini-Srasra and Srasra, 2008; Acebal and Vico, 2017). The porous structure of this clay allows the insertion and/or adsorption of organic molecules and ions, making it a good adsorbent (Giustetto et al., 2014; $\mathrm{Mu}$ and Wang, 2016). Recent studies involving dyes and PAL clay have obtained several novel Maya Blue-like pigments (Lima et al., 2012; Fan et al., 2014; Zhang et al., 2015a, 2015b; Zhang et al., 2015c, 2015d), some of which are materials with interesting self-cleaning properties (Zhang et al., 2016a, 2016b). Adsorption of dyes onto PAL and PAL composites (Mu and Wang, 2016) and biomedical applications clay-drug hybrid materials (Kim et al., 2016) have been recently reviewed and the use of PAL as an adsorbent for environmental remediation continues to be of interest (Ugochukwu et al., 2013; Boudriche et al., 2015; Yang et al, 2018).

The chromophoric group of anthocyanins, which are responsible for most of the purple, blue and red colors of flowers and fruits, is a 7-hydroxyflavylium cation. The chemical and photochemical reactivity of synthetic flavylium cations mimics that of natural anthocyanins, with the advantage of the facility and versatility of modifying the substituents on the flavylium chromophore and consequently their reactivity. Although anthocyanins and synthetic flavylium cations have great potential for practical applications as dyes or antioxidants, these applications are limited by their chemical reactivity, which is affected by several factors including $\mathrm{pH}$, temperature, light, oxygen, among others (Ferreira da Silva et al., 2005; Castañeda-Ovando et al., 2009; Quina et al., 2009; Cavalcanti et al., 2011; Silva et al., 2016).

The inclusion and/or adsorption of anthocyanins and flavylium cations in/on inorganic substrates such as mesoporous materials (Kohno et al., 2008a, 2011, 2015; Gago et al., 2017) and clays (Lima et al., 2007; Kohno et al., 2007, 2009, 2010; Ogawa 
et al., 2017; Ribeiro et al., 2018), may represent promising alternatives for preventing the undesirable chemistry of these dye molecules. In the present work, we have investigated the preparation of flavylium cation/palygorskite (FL/PAL) complexes as prototypes for fluorescent hybrid anthocyanin/palygorskite pigments. The complexes that retained the more intense colors and fluorescence after exhaustive washing with acidic methanol were chosen for evaluation of the thermal, photochemical and $\mathrm{pH}$ stability of their color and fluorescence.

\section{Experimental Section}

\subsection{Materials}

The flavylium cation salts 3',4',7-trimethoxyflavylium chloride (FL1), 7hydroxy-4'-methoxy-flavylium chloride (FL2), 7-hydroxy-4-methylflavylium chloride (FL3), 5,7-dihydroxy-4-methylflavylium chloride (FL4) and 7-methoxy-4methylflavylium chloride (FL5) used in this work (Scheme 1) were available from previous studies of the group and the syntheses have been previously reported (Freitas et al., 2013; Held et al., 2016; Silva et al., 2018). The palygorskite used in this work was the Source Clay PFl-1 from the Clay Minerals Society. The chemical composition, characterization and properties of this clay have been described (Shariatmadari et al., 1999; Borden and Giese, 2001; Chipera and Bish, 2001; Guggenheim and Koster van Groos, 2001; Madejová and Komadel, 2001; Mermut and Cano, 2001; Li et al., 2003; Dogan et al., 2006; Frost et al., 2010). Hydrochloric acid (HCl, Vetec) was used as received, methanol (Merck) was treated with sodium and ultrapure water was used for the preparation of all aqueous solutions. 
<smiles>COc1ccc2ccc(-c3ccc(OC)c(OC)c3)[o+]c2c1</smiles>

FL1<smiles>COc1ccc(-c2ccc3ccc(O)cc3[o+]2)cc1</smiles>

FL2<smiles>Cc1cc(-c2ccccc2)[o+]c2cc(O)ccc12</smiles>

FL3<smiles>Cc1cc(-c2ccccc2)[o+]c2cc(O)cc(O)c12</smiles>

FL4<smiles>COc1ccc2c(C)cc(-c3ccccc3)[o+]c2c1</smiles>

FL5

Scheme 1. Structures of the flavylium cations (FL) used in this work.

\subsection{Preparation and physical characterization of the FL/PAL Hybrid Pigments}

Aliquots of solutions of the FL in methanol (in which FL cations are highly soluble) containing $1 \% 1.0 \mathrm{~mol} \mathrm{dm} \mathrm{d}^{-3} \mathrm{HCl}$ (in order to suppress proton transfer and hydration of the flavylium cations) were added to the appropriate amount of PAL clay powder. The initial FL/PAL ratios utilized were $0.050,0.075,0.100$ and $0.125 \mathrm{mmol} \mathrm{g}^{-1}$. The resulting dispersions were stirred for $24 \mathrm{~h}$ in the dark at room temperature, centrifuged and the solid washed exhaustively with $\mathrm{HCl}$-acidified methanol and dried at $45^{\circ} \mathrm{C}$ under vacuum for $2 \mathrm{~h}$. The amount of flavylium cation adsorbed was estimated from the decrease in the absorbance of the supernatant employing the known molar attenuation coefficient of each FL.

Powder X-ray diffractograms of PAL and FL1/PAL were determined with a Bruker D2 Phase diffractometer using $\mathrm{Cu}-\mathrm{K}_{\alpha}$ radiation $(1.5418 \AA, 30 \mathrm{kV}, 15 \mathrm{~mA})$ employing a scan step of $0.05^{\circ}$. Nitrogen adsorption/desorption isotherms were determined at $-196{ }^{\circ} \mathrm{C}$ using a Quantachrome volumetric adsorption analyzer (Model $100 \mathrm{E})$. The samples were outgassed for $24 \mathrm{~h}$ under reduced pressure at $80^{\circ} \mathrm{C}$. The specific 
surface areas $\left(\mathrm{S}_{\mathrm{BET}}\right)$ and total pore volumes $\left(\mathrm{V}_{\mathrm{tot}}\right)$ of the samples were determined by the BET (Brunauer et al., 1938) and BJH (Barrett et al., 1951) methods, respectively. Surface areas of the micropores $\left(\mathrm{S}_{\text {micro }}\right)$, the external surface areas $\left(\mathrm{S}_{\mathrm{ext}}\right)$, the micropore volumes $\left(\mathrm{V}_{\text {micro }}\right)$ and the sum of meso- and macropore volumes $\left(\mathrm{V}_{\text {meso+macro }}\right)$ were estimated by the $t$-plot method (Lippens and de Boer, 1965).

\subsection{Spectroscopic measurements}

For the infrared measurements, about $1.50 \mathrm{mg}$ of solid sample was added to approximately $150 \mathrm{mg}$ of dry $\mathrm{KBr}$ in a small agate mortar and mixed by grinding. The resulting powder was pressed into a pellet using a hydraulic press (Caver, model 3912, Wabash). Infrared spectra of the pellets were collected using a Bruker Vector 22 FTIR spectrophotometer in the frequency range of $4000-500 \mathrm{~cm}^{-1}, 32$ scans at $0.5 \mathrm{~cm}^{-1}$ digital resolution.

The UV-Vis-diffuse reflectance (DR) spectra were measured with a Varian Cary $50 \mathrm{UV}$-vis Bio spectrophotometer equipped with a Barrelino ${ }^{\mathrm{TM}}$ diffuse reflectance probe (Harrick Scientific Products, Inc.). Samples with greater amounts of adsorbed flavylium (FL1 and FL2) were diluted in barium sulfate. The diffuse reflectance spectra were converted to the corresponding reemission function, $\mathrm{F}(\mathrm{R})$, employing the Kubelka-Munk equation (Tomasini et al., 2009):

$$
F(R)=\frac{(1-R)^{2}}{2 R}
$$

where $\mathrm{R}$ is the measured reflectance at each wavelength. CIELAB Color coordinates (CIE L*a*b*) (Gilchrist and Nobbs, 1999) were obtained from the UV-vis-DR measurements by using the software Agilent Cary WinUV Color. In this case, the samples were not diluted in barium sulfate in order to obtain the true color coordinates of the samples. 
172 Absorbance spectra were measured using the same spectrophotometer or a Hewlett 173 Packard 8452A diode array spectrometer.

All steady state fluorescence measurements were performed with a Hitachi F-4500 equipped with a solid sample holder. The excitation and emission wavelengths are indicated in the figure legends. The slits were set to bandwidths of $5.0 \mathrm{~nm}$ for both excitation and emission monochromators of the hybrid pigments, and for FL1 and FL2 were 10/20 and 2.5/5.0 $\mathrm{nm}$ (excitation and emission), respectively. The experiments with the hybrid pigments were conducted in the solid state. For the steady-state fluorescence anisotropy measurements, the fluorescence spectrophotometer (Hitachi F-4500) was fitted with manual polarizers placed in the excitation and emission light pathways. The steady-state anisotropy (r) was calculated for the emission intensities determined for the

where $G=I_{H V} / I_{H H}$ is a correction factor for the relative sensitivity of the detection system to horizontally and vertically polarized light.

Time-resolved fluorescence decay experiments were carried out using an OB920 single photon counting system (Edinburgh Instruments), exciting the sample with a 405 nm Picosecond Pulsed Diode Laser (EPL405). The solid sample was placed in a shallow quartz cell that was covered with a quartz glass and was placed in a front-face sample holder which is tilted so as to minimize specular reflections (Zhang et al., 2014). The bandwidth for the emission monochromator was $16 \mathrm{~nm}$. A neutral density filter was employed for control of the photon flux from the excitation source that reached the 
sample. The emission wavelengths set for the collection of the decays for the FL1/PAL and FL2/PAL samples were 575 and $525 \mathrm{~nm}$, respectively. The fluorescence decays were collected with a 50 ns time window and the number of counts in the channel with maximum intensity was 10,000 . Barium sulfate powder was used as a scatterer to collect the instrument response function (IRF). The fluorescence decays were fit to a sum of exponentials employing Edinburgh Instruments F900 software for reconvolution to extract the lifetimes. The quality of the fits was determined by the randomness of the residuals and the $\chi^{2}$ values, which are ideally between 0.9 and 1.3.

For the anisotropy experiments, the diode laser was rotated to achieve vertical and horizontal polarizations of the excitation beam. For the emission collection, the polarizer between the sample and the emission monochromator was set to the required angles. The anisotropy decay measurements were performed with a $20 \mathrm{~ns}$ time window and the time required to collect 10000 counts was estimated. This time and the neutral density setting for the excitation beam were kept constant for the collection of the 4 decays with the different polarizations. The four decays were collected for each anisotropy calculation $\left(I_{V V}, I_{V H}, I_{H V}, I_{H H}\right)$ and combined to obtain the anisotropy decay (Lakowicz, 2006):

$$
r(t)=\frac{I_{V V}(t)-G I_{V H}(t)}{I_{V V}(t)+2 G I_{V H}(t)}
$$

The anisotropy decay, calculated using the F900 software, was then fit to a sum of exponentials to estimate rotational correlation lifetimes.

\subsection{Wide Field and Confocal Fluorescence Microscopy}

Confocal fluorescence images were obtained using a plate scanning instrument based on a microscope (Olympus IX71) with a digital piezoelectric controller and stage (PI, E-710.3CD and P-517.3CD) for nanometric sample scanning. The excitation of the samples at $473 \mathrm{~nm}$ was provided by a Cobolt Blue diode laser. The circularly polarized 
laser beam was focused on the samples with an UPLFLN 40X Olympus objective. The emission signal was separated from the laser excitation beam using Chroma Z470rd and ZET 473NF dichroic and notch filter, respectively. Photons were counted using an avalanche photodiode point detector (Perkin Elmer, SPCM-AQR-14) aligned with a 50 $\mu \mathrm{m}$ pinhole in the confocal line. Transistor-transistor logic (TTL) detector signals were registered in a counter/timer PCI card (NI 6601) and transferred to a personal computer for 2D plotting using a scanning control program written in C\# (Ferreira et al., 2011). Fluorescence images were recorded using false-color mapping, reaching the best contrast enhancement according to the difference in intensity of the fluorescence signal. Widefield images were obtained with the same fluorescence microscope by adapting an optical lens in the epifluorescence entrance with focus on the back aperture of the objective. The samples were excited at $405 \mathrm{~nm}$ with a Coherent Cube CW laser and the emission was selected by a dichroic cube (Chroma, z4051p) and images were registered in a color camera (ThorLabs DCU223C) coupled to the right primary port of the Olympus IX71 (Lauer et al., 2014).

\subsection{Photochemical and Thermal stability and sensitivity to $\mathrm{pH}$}

The UV radiation resistance tests of the samples were performed using an Oriel $^{\circledR}$ (California, USA) Sol UV-2 Solar simulator (85.7 \% UV-A, $11 \%$ UV-B and $3.3 \%$ of visible light). The samples were exposed to a radiation intensity of $75.0 \mathrm{~W} \mathrm{~m}^{-2} \mathrm{UV}-\mathrm{A}$ $(365 \mathrm{~nm})$ and $43.0 \mathrm{~W} \mathrm{~m}^{-2} \mathrm{UV}-\mathrm{B}(312 \mathrm{~nm})$. The irradiations were carried out at room temperature $\left(25^{\circ} \mathrm{C}\right)$ with an exposure time of $6 \mathrm{~h}$. UV-vis-DR measurements were used to verify any spectral and color changes.

In order to verify the reactivity of the FL cations adsorbed into/onto PAL, FL1/PAL and FL2/PAL samples were added to $5 \mathrm{~mL}$ of $10 \mathrm{mmol} \mathrm{dm}^{-3}$ phosphate buffer 
solution at $\mathrm{pH}=9$. After $24 \mathrm{~h}$, the samples were centrifuged and dried. UV-vis-DR measurements were used to verify any spectral and color changes. In order to compare the stability of the hybrid pigments with the respective free FL, the spectra of FL in 10 mmol dm ${ }^{-3}$ phosphate buffer solution, $\mathrm{pH}=8.5$, were also obtained. The reversibility was examined by adding FL to $10 \mathrm{mmol} \mathrm{dm}^{-3}$ acetate buffer solutions at $\mathrm{pH}=4,5$ or 6 , followed by addition of $0.1 \mathrm{~g}$ of PAL after discoloration of the solutions due to hydration of the flavylium cation. This test was carried out under stirring at room temperature (ca. $20^{\circ} \mathrm{C}$ ) and accomplished by taking digital images as a function of the time.

Thermal stability was investigated by submitting FL1/PAL and FL2/PAL samples to heating at $120{ }^{\circ} \mathrm{C}$ under vacuum for $24 \mathrm{~h}$ and comparing with FL cations in solid form that were submitted to the same temperature for $2 \mathrm{~h}$. Measurements of the color coordinates and digital images were used to verify any color changes.

\section{Results and discussion}

\subsection{Hybrid Pigment Formation}

Initial studies clearly showed that the relative amount of flavylium cation adsorbed and the colors of the samples were influenced by the substituents on the FL cations. Five FL cations with similar substituents at different positions but with different $\mathrm{pH}$-dependent equilibria and different molecular sizes and solvophobicity/solvophilicity, were chosen for evaluation. Both FL1 and FL2 adsorbed strongly on PAL (Table 1) and imparted attractive colors to the samples (Figure S1 of the Supplementary Material), even after exhaustive washing with acidic methanol with the objective of removing loosely physiosorbed dye. In contrast, the other three flavylium cations all have a methyl group at the 4-position, i.e., FL3, FL4 and FL5, and all adsorbed poorly on PAL, failing to impart attractive coloration to the clay. In the case of FL4, the amount adsorbed was 
miniscule, as shown in Table 1 and in Figure S2 of the Supplementary Material. Since affinity and stability should parallel each other, our subsequent studies of the hybrid pigments focused on those derived from FL1 and FL2, i.e., FL1/PAL and FL2/PAL, respectively.

Table 1. Relative amounts of flavylium cation adsorbed, in $\mu$ mol per $g$ of PAL.

\begin{tabular}{c|ccccc}
\hline $\begin{array}{c}\text { Initial FL/PAL } \\
\text { ratio }\end{array}$ & FL1 & FL2 & FL3 & FL4 & FL5 \\
\hline 50 & 40 & 24 & 12 & $<0.1$ & $<1$ \\
75 & 59 & 29 & 7 & $<0.1$ & 9 \\
100 & 67 & 31 & 19 & $<0.1$ & 3 \\
125 & 72 & 33 & 12 & $<0.1$ & 14 \\
\hline
\end{tabular}

\subsection{X-Ray Diffraction and $\mathrm{N}_{2}$ adsorption isotherms}

The powder X-ray diffractograms of FL1/PAL with the highest dye loading were indistinguishable from that of the raw PAL clay itself (Figure S3 of the Supplementary Material), which was in turn the same as that published for the raw PFl-1 Source Clay (Chipera and Bish, 2001). This is an expected result since the dye loading was nonetheless still relatively low and the interlayer spacings of one-dimensional clays such as palygorskite are known to be fairly insensitive to the inclusion of organic molecules (Giustetto et al., 2014; Chang et al., 2016; Yang et al., 2018).

Table 2 shows the specific surface areas $\left(\mathrm{S}_{\mathrm{BET}}\right)$ and total pore volumes $\left(\mathrm{V}_{\mathrm{tot}}\right)$ of the FL1/PAL and FL2/PAL samples with the highest amounts of adsorbed dyed (72 and $33 \mu \mathrm{mol} \mathrm{g}^{-1}$, respectively) and of a PAL reference sample exhaustively washed with methanol containing $1 \% 1.0 \mathrm{~mol} \mathrm{dm}^{-3} \mathrm{HCl}$ determined from $\mathrm{N}_{2}$ adsorption isotherms by the BET (Brunauer et al., 1938) and BJH (Barrett et al., 1951) methods, respectively.

Table 2 also indicates the surface areas of the micropores $\left(S_{\text {micro }}\right)$, the external surface areas $\left(\mathrm{S}_{\mathrm{ext}}\right)$, the micropore volumes $\left(\mathrm{V}_{\text {micro }}\right)$ and the sum of meso- and macropore volumes 
$294\left(\mathrm{~V}_{\text {meso+macro }}\right)$ estimated by the $t$-plot method (Lippens and de Boer, 1965). For FL1/PAL,

295 the reduction in surface area was primarily due to the decrease in the external area $S_{\text {ext }}$,

296 while FL2/PAL exhibited decreases in both the external and micropore surface areas and

297 in the accessible pore volumes.

298

299 Table 2: Surface areas and pore volumes of acid-washed PAL, FL1/PAL = 72 and 300 $\mathrm{FL} 2 / \mathrm{PAL}=33$.

\begin{tabular}{ccccccc}
\hline Sample & $\mathbf{S}_{\text {BET }} / \mathbf{m}^{\mathbf{2}} \mathbf{g}^{-\mathbf{1}}$ & $\mathbf{S}_{\text {micro }} / \mathbf{m}^{\mathbf{2}} \mathbf{g}^{-\mathbf{1}}$ & $\mathbf{S}_{\text {ext }} / \mathbf{m}^{\mathbf{2}} \mathbf{g}^{-\mathbf{1}}$ & $\mathbf{V}_{\text {micro }} / \mathbf{c m}^{\mathbf{3}} \mathbf{g}^{-\mathbf{1}}$ & $\begin{array}{c}\mathbf{V}_{\mathbf{m e s o}+\mathbf{m a c r o}} / \\
\mathbf{c m}^{\mathbf{3}} \mathbf{g}^{-\mathbf{1}}\end{array}$ & $\mathbf{V}_{\text {tot }} / \mathbf{c m}^{\mathbf{3}} \mathbf{g}^{-\mathbf{1}}$ \\
\hline PAL & 137 & 21 & 116 & 0.011 & 0.475 & 0.486 \\
FL1/PAL & 126 & 22 & 104 & 0.011 & 0.462 & 0.473 \\
FL2/PAL & 126 & 15 & 111 & 0.008 & 0.420 & 0.428
\end{tabular}

$301{ }^{a}$ after washing with $\mathrm{HCl}$-acidified methanol.

302

303

\subsection{Spectroscopic and Photophysical Studies}

304

FTIR spectra of PAL clay and of the FL1 and FL2 derived hybrid pigments were

305 recorded in the region from $4000 \mathrm{~cm}^{-1}$ to $500 \mathrm{~cm}^{-1}$ (Figure $\mathrm{S} 4$ of the Supplementary

306 Material). The raw clay exhibits absorption bands in the range $3000-3600 \mathrm{~cm}^{-1}$, along

307 with a band at $1654 \mathrm{~cm}^{-1}$, corresponding respectively to the stretching and bending

308 vibrations of water molecules (coordinated and zeolitic) (Frost et al., 2010; Giustetto and

309 Wahyudi, 2011; Fan et al., 2014; Zhang et al., 2015b; Zhang et al., 2015c, 2015d). The

310 region $3000-3600 \mathrm{~cm}^{-1}$ also includes contributions from the $\mathrm{OH}$-stretching vibrations of

311 Mg/Al-OH groups (Frost et al., 2010; Zhang et al., 2015a; Zhang et al., 2015d). The band

at $3615 \mathrm{~cm}^{-1}$ corresponds to Al-OH stretching (Frost et al., 2010; Zhang et al., 2015b;

Zhang et al., 2015d) and/or Si-OH stretching (Giustetto and Wahyudi, 2011). Bands in 
et al., 2015b; Zhang et al., 2015c) and the weak band at $797 \mathrm{~cm}^{-1}$ is characteristic of quartz impurities (Frost et al., 2010; Zhang et al., 2015b). In the infrared spectra of the FL/PAL samples, additional bands characteristic of FL cations were detected in the range of 1200$1600 \mathrm{~cm}^{-1}$ (Figure 1). In particular, the absorption bands at $1356 \mathrm{~cm}^{-1}$ and $1352 \mathrm{~cm}^{-1}$ for FL1/PAL and FL2/PAL samples, respectively, correspond to C-O-C stretching. The intensities of the FL bands are quite weak because of the relatively small amount of flavylium cation in relation to clay and exhibit hypsochromic shifts compared to the FL cation salts, reflecting the interactions between FL and PAL.

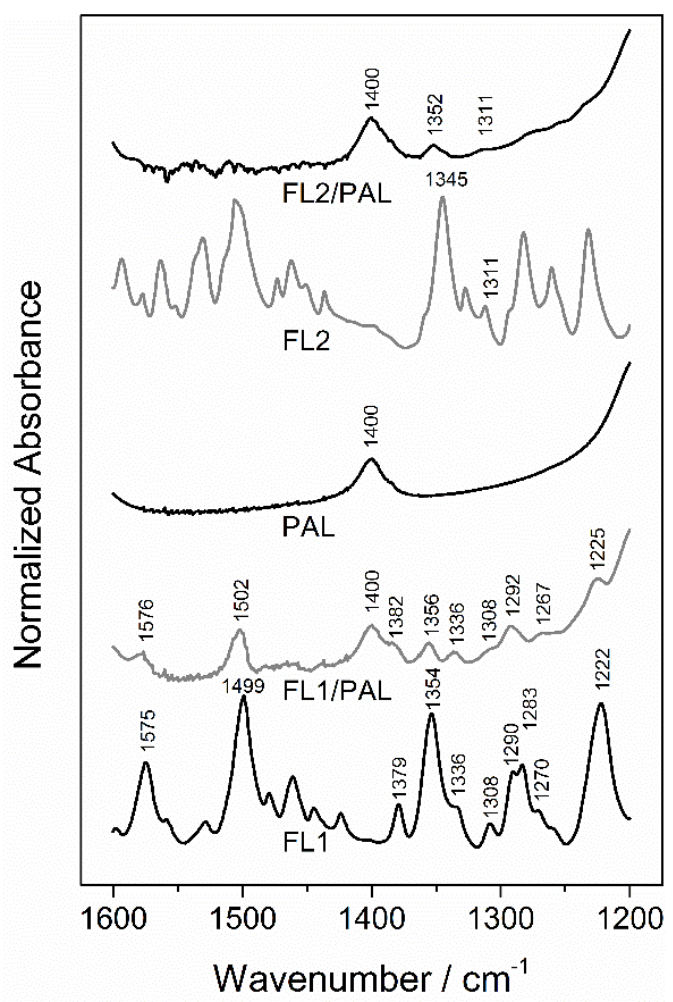

Figure 1. Infrared spectra of PAL, FL1, FL2, FL1/PAL (72 $\mu \mathrm{mol})$ and FL2/PAL (33 $\mu \mathrm{mol})$ in the range $1200-1600 \mathrm{~cm}^{-1}$. Note: The broad peak at $1400 \mathrm{~cm}^{-1}$ is an impurity in the $\mathrm{KBr}$ used.

UV-vis absorption spectra of FL1 and FL2 in $1 \% 1.0 \mathrm{~mol} \mathrm{dm}^{-3} \mathrm{HCl} / \mathrm{methanol}$ solution present absorption maxima at 478 and $465 \mathrm{~nm}$, respectively (Figures 2a and 2b). The UV-vis-DR spectra of the hybrid pigments in the same Figures exhibit a small red 
shift from $478 \mathrm{~nm}$ to around $492 \mathrm{~nm}$ for FL1, and $465 \mathrm{~nm}$ to $470 \mathrm{~nm}$ for FL2. Spectral shifts of this type have been attributed to the effect of electrostatic interactions between organic molecules and the inorganic substrate (Kohno et al., 2008a, 2009) or to the acidity of the inorganic substrate (Kohno et al., 2008b). Although aggregates are relatively common for the adsorption of dyes on clays (Valandro et al., 2015, 2017), the spectra did not present any evidence of the presence of FL aggregates, indicating that the washing step as part of the adsorption procedure efficiently removed excess FL cations that might participate in aggregate formation.
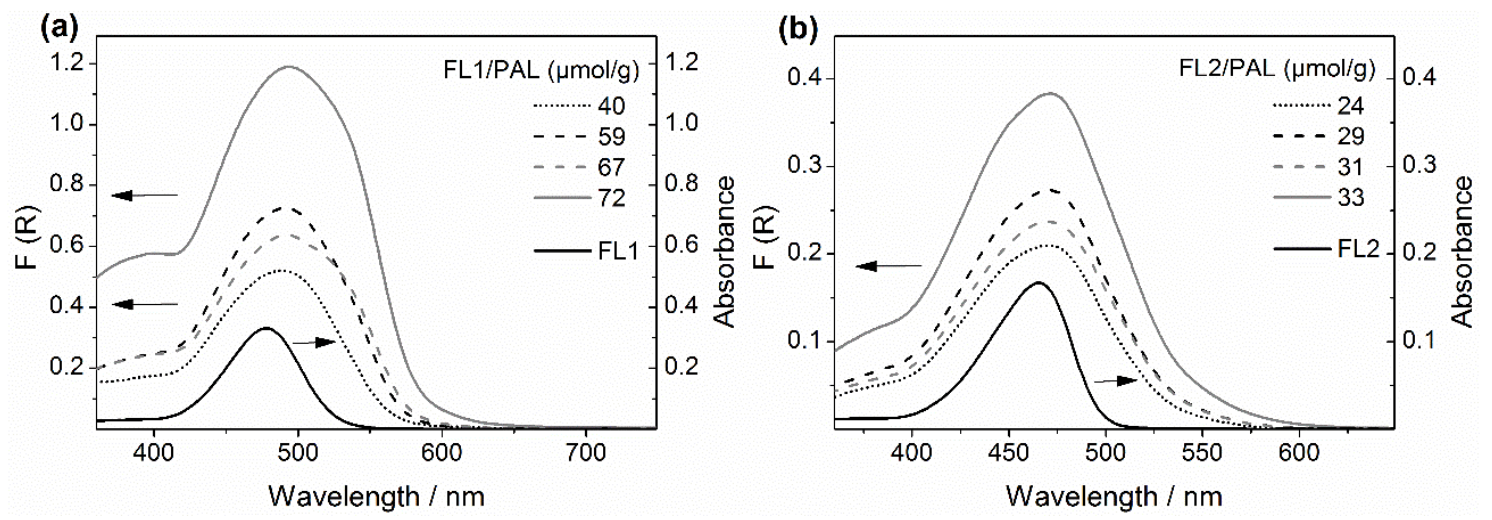

Figure 2. UV-vis and UV-vis-DR spectra (Kubelka-Munk mode) of (a) FL1 and FL1/PAL, and (b) FL2 and FL2/PAL samples.

Figure 3 shows the fluorescence excitation and emission spectra of the hybrid pigments FL1/PAL and FL2/PAL, together with those of FL1 and FL2 in 1\% $1.0 \mathrm{~mol} \mathrm{dm}^{-}$ ${ }^{3} \mathrm{HCl} /$ methanol solution. In $1 \% 1.0 \mathrm{~mol} \mathrm{dm}{ }^{-3} \mathrm{HCl} /$ methanol solution, FL1 presented a broad fluorescence emission band with a maximum around $577 \mathrm{~nm}$ and FL2 a maximum at $509 \mathrm{~nm}$. The corresponding fluorescence excitation spectra resemble the absorption spectra, with maxima at 487 and $468 \mathrm{~nm}$ for FL1 and FL2, respectively. The two hybrid pigments showed emission in the same region as the corresponding FL in solution. For FL2/PAL, the maximum fluorescence emission was at ca. $525 \mathrm{~nm}$ and did not shift significantly with increasing amount of adsorbed FL. For FL1/PAL, however, the 
352

353

354

355

356

357

358

359

360

361

362

363

364

365

366

367

368

369

370

371

fluorescence emission maximum underwent a red-shift from 577 to $600 \mathrm{~nm}$ with increasing amount of adsorbed FL1. In the case of Auramine O adsorbed on SYn-1 and SAz-1 clays, a decrease in intensity and shift to longer wavelengths of the fluorescence emission with increasing dye adsorption was attributed to H-aggregate formation (Valandro et al., 2015). However, FL/PAL hybrid pigments exhibited no additional absorption bands of the type expected for J- or H-aggregates, suggesting that the apparent shift with increasing adsorbed FL1 is more likely a distortion of the emission spectrum due to reabsorption, i.e., to an inner filter effect. For both solid hybrid pigments, the frontface geometry emission intensity decreased as the amount of adsorbed flavylium cation increased (Figure 3), suggesting self-quenching.

(a)

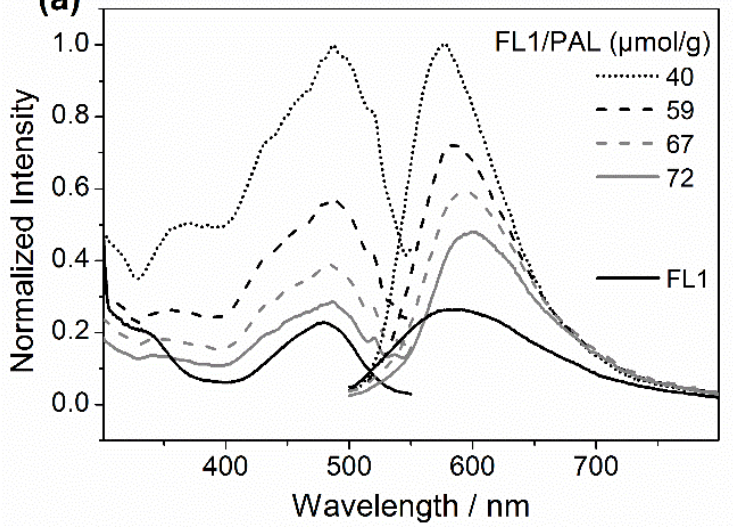

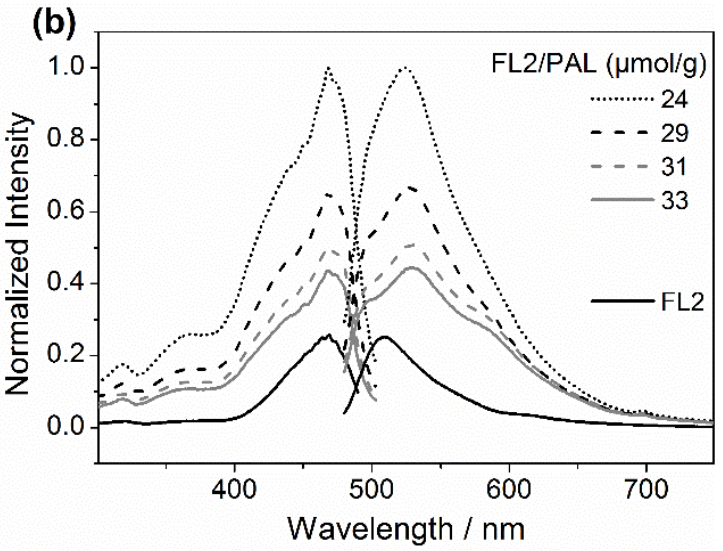

Figure 3. Excitation and emission spectra of (a) FL1 (Ex. 480 and Em. $576 \mathrm{~nm}$ ) in 1\% $1.0 \mathrm{~mol} \mathrm{dm}{ }^{-3} \mathrm{HCl} / \mathrm{methanol} \mathrm{solution} \mathrm{and} \mathrm{solid} \mathrm{FL1/PAL} \mathrm{(Ex.} 470$ and Em. 576 nm; adsorbed amounts of FL1 are indicated in $\mu \mathrm{mol} / \mathrm{g}$ ); (b) FL2 (Ex. 467 and Em. $508 \mathrm{~nm}$ ) in $1 \% 1.0 \mathrm{~mol} \mathrm{dm} \mathrm{d}^{-3} \mathrm{HCl} /$ methanol solution and solid FL2/PAL (Ex. 467 and Em. 525 nm; adsorbed amounts of FL1 are indicated in $\mu \mathrm{mol} / \mathrm{g}$ ) samples.

Time-resolved emission measurements (405 nm excitation; $575 \mathrm{~nm}$ emission for FL1/PAL and $525 \mathrm{~nm}$ emission for FL2/PAL) indicated fast biexponential decay with 
lifetimes $( \pm 15 \%)$ of FL1/PAL ( 0.35 and 1.0 ns with normalized preexponentials of ca. 0.8 and 0.2 , respectively) about half those of FL2/PAL ( 0.6 and 2.0 ns with normalized preexponentials of ca. 0.6 and 0.4 , respectively). Steady-state fluorescence anisotropies ( $r$ ) ranged from 0.03-0.05 for FL1/PAL and 0.06-0.07 for FL2/PAL, apparently insensitive to the amount of adsorbed FL. Time-resolved anisotropy measurements showed an extremely fast initial depolarization, within ca. $\leq 100 \mathrm{ps,} \mathrm{with} \mathrm{a} \mathrm{residual}$ anisotropy at long times consistent with that found in the steady-state measurements. This suggests that fast intermolecular energy transfer or migration between FL molecules is the main mechanism responsible for the rapid loss of anisotropy and could also contribute to the decrease in fluorescence intensity with increasing amount of adsorbed flavylium cation.

Wide field fluorescence images (Figure S5 of the Supplementary Material; true color) indicate a homogeneous distribution of adsorbed FL without differentiating between adsorption inside or on the edges of the channels, with the difference in intensities due largely to differences in the focal planes. In agreement with the red shift of the emission seen in the fluorescence spectra, the fluorescence color of the FL1/PAL particles changes with the amount of FL1 adsorbed, as can be seen in Figure S5 of the Supplementary Material. Images recorded by confocal fluorescence microscopy using false-color mapping are shown in Figure S6 of the Supplementary Material. Although these images indicate that the particles are not homogeneous in size or shape, all are strongly fluorescent, with the highest intensities in the regions of the focal plane around the particle core. Unfortunately, the dye loadings were much too high to make singlemolecule measurements on isolated particles or fibers (Martínez-Martínez et al., 2011).

\subsection{Stability Tests of the Hybrid Pigments}


Resistance of the adsorbed dye to extraction with organic solvent and acid is, in essence, intrinsic to the method of preparation of the hybrid pigments. Thus, the flavylium dissolved in acidic methanol were allowed to adsorb by contact with the clay and the resultant materials then washed exhaustively with acidic methanol to remove any readily extractable dye. Although the dyes are also highly soluble in water, water did not extract the dye from either FL1/PAL or FL2/PAL.

The photochemical stability of flavylium cations is usually much better than their thermal stability. Indeed, both the solid pigments and the hybrid pigments showed good photostability, with the color being essentially unaltered by irradiation for $6 \mathrm{~h}$ in a solar UV simulator. Thus, adsorption of the dyes onto the clay does not markedly reduce their photostability. On the other hand, there was substantial improvement in the thermal stability of both FL1 and FL2 adsorbed on palygorskite, as has been reported for flavylium cations adsorbed on other types of clay (Kohno et al., 2007, 2010) or protonated zeolites (Kohno et al., 2008a). A temperature of $120{ }^{\circ} \mathrm{C}$. was chosen for the thermal stability tests since temperatures up to $120-150{ }^{\circ} \mathrm{C}$ have been used for the thermal analysis sepiolite/indigo and PAL/indigo hybrid materials (Hubbard et al., 2003) and, in the case of PAL (Guggenheim and Koster van Gross, 2001), this temperature is just above the range where most of the weakly adsorbed water has been lost and where the more strongly adsorbed water only begins to be lost. Thus, while both FL1 and FL2 degraded substantially in less than $2 \mathrm{~h}$ at this temperature in a vacuum oven, both hybrid pigments largely retained their characteristic colors (Table 3 and Figures S7-S9 and Tables S1 and S2 of the Supplementary Material) after $24 \mathrm{~h}$ under these conditions.

Table 3. CIELAB color coordinates for the hybrid pigments before and after heating at $120^{\circ} \mathrm{C}$. for $24 \mathrm{~h}$. 


\begin{tabular}{ccccc}
\hline Samples & & L* & $\mathrm{a}^{*}$ & $\mathrm{~b}^{*}$ \\
$\mathrm{FL} 1 / \mathrm{PAL}=72$ & $\begin{array}{c}\text { Before } \\
\text { heating }\end{array}$ & 55.8438 & 50.5605 & 58.3429 \\
$\mathrm{FL} 1 / \mathrm{PAL}=72$ & $\begin{array}{l}\text { After } 24 \mathrm{~h} \\
\text { at } 120^{\circ} \mathrm{C} .\end{array}$ & 51.1756 & 43.4934 & 52.4811 \\
$\mathrm{FL} 2 / \mathrm{PAL}=33$ & $\begin{array}{c}\text { Before } \\
\text { heating }\end{array}$ & 73.6264 & 17.4510 & 79.0872 \\
$\mathrm{FL} 2 / \mathrm{PAL}=33$ & $\begin{array}{l}\text { After } 24 \mathrm{~h} \\
\text { at } 120^{\circ} \mathrm{C} .\end{array}$ & 60.3541 & 28.2977 & 56.6914 \\
\hline
\end{tabular}

422

In aqueous solution, both FL1 and FL2 undergo hydration above about $\mathrm{pH} 3$ to form the hemiacetal (B), followed by ring-opening tautomerization to form the cischalcone (ZC) and then slow isomerization to the trans-chalcone (EC) (Held et al., 2016). The 7-hydroxy group of FL2 can also deprotonate at slightly higher $\mathrm{pH}$, resulting in the conjugate base (A); the corresponding equilibria are shown for FL2 in Scheme S1 of the Supplementary Material. Spectra of FL1 or FL2 registered after $1 \mathrm{~h}$ in $\mathrm{pH}=8.5$ phosphate buffer solution and of the hybrid pigments after immersion for $24 \mathrm{~h}$ in $\mathrm{pH}=9$ phosphate buffer solution are shown in Figure 4. For FL1 a new band appeared around $380 \mathrm{~nm}$ corresponding to a mixture of B, ZC and EC, while FL2 presented two new bands, one at around $490 \mathrm{~nm}$ assigned to a conjugate base formed by deprotonation of the hydroxyl group of one or more of the species resulting from the hydration-induced equilibria. The spectra of FL1/PAL and FL2/PAL also showed two bands at longer wavelength, one in the region of the adsorbed cation and the other in the same regions as FL1 and FL2 in solution at similar alkaline $\mathrm{pH}$. 
(a)

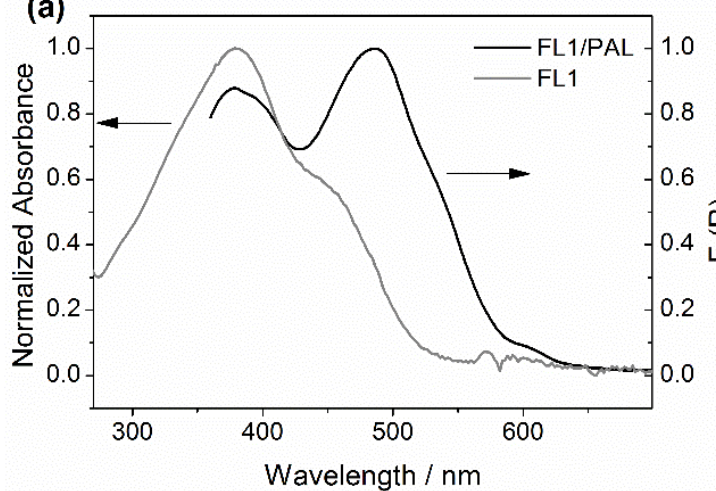

(b)

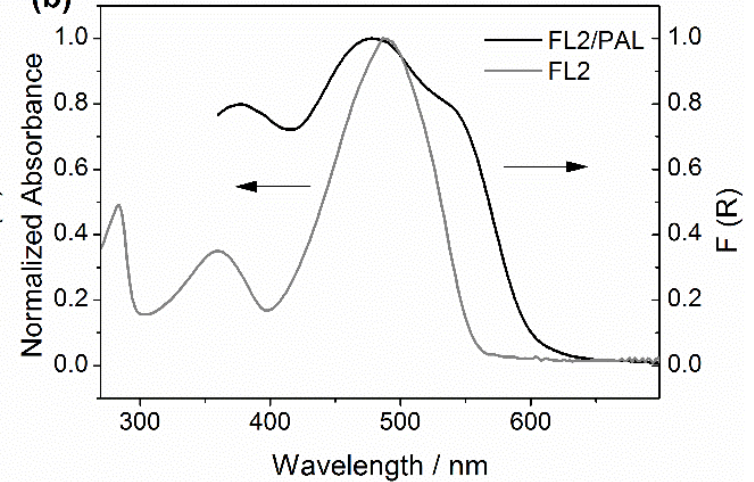

439

Figure 4. Absorbance and diffuse reflectance spectra (Kubelka-Munk mode) for (a) FL1 and FL1/PAL and (b) FL2 and FL2/PAL. The absorbance spectra were collected for FL1 and FL2 incubated for $1 \mathrm{~h}$ in $\mathrm{pH} 8.5$ solution, and the UVvis-DR spectra were collected after FL1/PAL and FL2/PAL were immersed for $24 \mathrm{~h}$ in $\mathrm{pH} 9$ solution, centrifuged and dried.

Figure S10 of the Supplementary Material illustrates the impact of the basic aqueous medium on the color of the hybrid pigments before and after immersion at $\mathrm{pH} 9$ and Table S3 of the Supplementary Material shows the CIELAB color coordinate data. Although the color of FL1/PAL became less intense upon immersion in $\mathrm{pH} 9$ aqueous solution, it still showed an attractive color compared to FL1 at the same $\mathrm{pH}$, indicating that the adsorption process made it less prone to hydration. However, FL2/PAL changed color completely, indicating that the adsorption process did not prevent deprotonation of a significant fraction of the adsorbed FL2 molecules. In both cases, the dye did not leach from the clay and the color changes were reversible upon acidification of the medium, indicating chemical stability under these conditions.

\subsection{The dye-clay interaction}

Since flavylium cations are highly soluble in methanol, the exhaustive washing with acidic methanol should remove any excess or weakly physiosorbed dye, leaving only strongly bound dye. This points to ion exchange as potentially the most important mode 
of interaction of these cationic dyes with palygorskite. In this regard, the final amounts of the flavylium cations adsorbed (Table 1) were all well below the cation exchange capacity (CEC) values reported for the PFl-1 Source Clay palygorskite utilized in this work: 175 (Borden and Giese, 2001) and 165 (Li et al., 2003) and, after a partial purification, $140 \mu \mathrm{mol} \mathrm{g}^{-1}$ (Shariatmadari et a., 1999). Nonetheless, because all five of the initially tested dyes are cationic, ion exchange alone cannot explain the marked differences in affinity for the clay. Thus, the presence of a methyl group at the 4 position of the flavylium chromophore of FL3 and FL5 substantially reduced the net adsorption and, in the case of FL4, the presence of an additional hydroxyl group at position 5 of the chromophore completely eliminated its adsorption after washing (Table 1). Indeed, as shown in Figure 5 (See Figure S11 in the Supplementary Material for a color version), the additional methyl group makes these compounds too wide to insert into the tunnels or external grooves of PAL. However, the two compounds without the 4-methyl group could insert partially, though not totally into the tunnels and/or interact with the open grooves on the external surface. Because FL2 is slightly smaller than FL1, it should fit into the tunnels somewhat better than FL1. This is consistent with the surface area and pore volume measurements (Table 2), which suggest a preference of FL1 for the external grooves and of FL2 for both external grooves and partial insertion into tunnels.

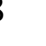

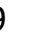
80 81 
483

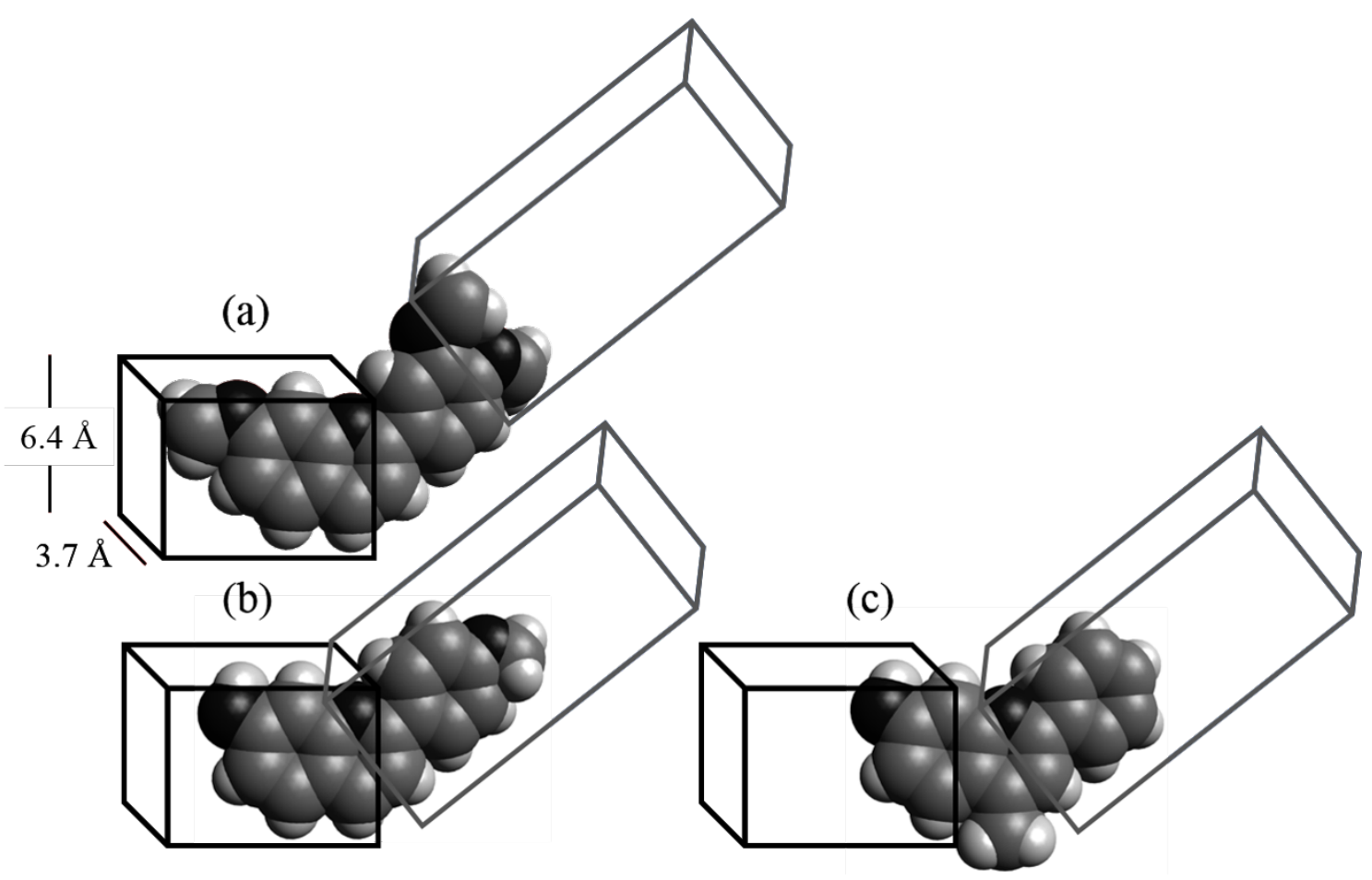

Figure 5. Comparison of the molecular sizes of (a) FL1, (b) FL2 and (c) FL3 with the dimensions of the tunnels of palygorskite (Brigatti et al., 2006).

Several studies have shown that the cationic form of anthocyanins and flavylium ions can be selectively stabilized aqueous solution by incorporating them into anionic micelles (Lima et al., 2002; Quina et al., 2009) or by inclusion in supramolecular complexes (Held et al., 2016). Because the apparent hydration constant of FL1 (pK $\mathrm{p}_{\mathrm{h}}$ or the $\mathrm{pH}$ at which half of the cation form is hydrated) is $3.0 \pm 0.3$ (Held et al., 2016), solutions of FL1 in acetate buffer at pH 4, 5 or 6 are nearly colorless (Figures S12-S14 of the Supplementary Material), reflecting the almost complete conversion of the flavylium cation form of FL1 to the hydrated species. Upon addition of PAL to these solutions, the suspended clay gradually acquired the red color of the adsorbed FL1 cation as a function of time, indicating the conversion of the hydrated forms in solution to the adsorbed cationic form on the clay. If only the cationic form adsorbed from solution onto the clay, there should be a clear difference in the apparent rates of adsorption at these three distinct 
$\mathrm{pH}$ values due to the large $\mathrm{pH}$-dependent differences in the equilibrium concentration of this form. However, the rates of appearance of the coloration were qualitatively very similar at $\mathrm{pH} 4$ and $\mathrm{pH}$ 5, but clearly much faster than at $\mathrm{pH}$ 6. Likewise, the maximum intensity of the color at long times ( 2 weeks) was similar for the two lower $\mathrm{pH}$ values, and much more intense than at $\mathrm{pH} 6$ (Figures S12-S14 of the Supplementary Material). Indeed, this strongly suggests that it is the hydrated forms that adsorb on PAL under these conditions and that they are subsequently converted to the cationic form by interaction with the more highly acidic sites of the clay with effective $\mathrm{pK}_{\mathrm{a}}$ around $\mathrm{pH}$ 5-5.5 (vide supra).

\section{Conclusions}

Simple electrostatic interactions are incompatible with the observed differences in adsorption of FL cations on PAL. The adsorption was particularly inefficient for FL cations bearing a 4-methyl group, consistent with steric inhibition of interaction with the palygorskite tunnels or external grooves as the major contributor to differences in adsorption. Adsorption on PAL stabilized the cationic form of the flavylium cations FL1 and FL2 against hydration to at least $\mathrm{pH}$, apparently reflecting the participation of the more highly acidic sites on the PAL surface. The photochemical stability was retained and the chemical and thermal stabilities of the cation form of FL1 and FL2 were substantially improved by adsorption on PAL, pointing to flavylium cations of this type as promising chromophores for the development of novel fluorescent hybrid pigments with attractive colors. 
524

525

526

527

528

529

530

531

532

533

534

535

536

537

538

539

540

541

542

543

544

545

546

547

548

\section{Acknowledgements}

The authors thank the CNPq (F.H.Q. Universal grant 408181/2016-3), INCT-Catálise, and NAP-PhotoTech for the support, the CNPq for a research productivity fellowships (F.H.Q. and M.H.G.), and CAPES for graduate fellowships (G.T.M.S. and C.P.S.). Researchers at UVic thanks NSERC (RGPIN-2017-04458) for funding and CAMTEC for the use of shared facilities. The authors thank Josué M. Gonçalves for assistance in determining the X-ray diffractograms and Dr. Thiago Lewis Reis Hewer, Dept. of Chemical Engineering, Polytechnic School, USP, for performing the $\mathrm{N}_{2}$ sorption measurements.

\section{References}

Acebal, S.G., Vico, L.I., 2017. Acid-Base Properties of Aqueous Suspensions of Homoionic Sepiolite and Palygorskite. Nat. Resour. 8, 432-444. https://doi.org/10.4236/nr.2017.86028

Arnold, E., Branden, J., 2008. The first direct evidence for the production of Maya Blue: rediscovery of a technology. Antiquity 82, 151-164. https://doi.org/10.1017/S0003598X00096514

Barrett, E. P., Joyner, L. G., Halenda, P. P. 1951. The Determination of Pore Volume and Area Distributions in Porous Substances. I. Computations from Nitrogen Isotherms. J. Am. Chem. Soc. 73, 373-380. https://doi.org/10.1021/ja01145a126

Borden, D., Giese, R. F. 2001. Baseline studies of the Clay Minerals Society source clays: Cation exchange capacity measurements by the ammonia-electrode method. Clays Clay Miner. 49, 444-445. https://doi.org/10.1346/CCMN.2001.0490510

Boudriche, L., Calvet, R., Chamayou, A., Hamdi, B., Balard, H., 2015. Removal of lead(II) from aqueous solution using modified palygorskite, contribution of inverse 
gas chromatography. J. Chromatogr. A 1408, 207-216. https://doi.org/10.1016/j.chroma.2015.07.011

551

Brigatti, M.F., Galan, E., Theng, B.K.G., 2006. Structures and Mineralogy of Clay Minerals, in: Chapter 2, Handbook of Clay Science, Developments in Clay Science. pp. 19-86. https://doi.org/10.1016/S1572-4352(05)01002-0

Brunauer, S., Emmett, P. H., Teller, E., 1938. Adsorption of Gases in Multimolecular Layers. J. Am. Chem. Soc. 60, 309-319. https://doi.org/10.1021/ja01269a023

Castañeda-Ovando, A., Pacheco-Hernández, M. de L., Páez-Hernández, M.E., Rodríguez, J.A., Galán-Vidal, C.A., 2009. Chemical studies of anthocyanins: A review. Food Chem. 113, 859-871. https://doi.org/10.1016/j.foodchem.2008.09.001

Cavalcanti, R.N., Santos, D.T., Meireles, M.A.A., 2011. Non-thermal stabilization mechanisms of anthocyanins in model and food systems-An overview. Food Res. Int. 44, 499-509. https://doi.org/10.1016/j.foodres.2010.12.007

Chang, P.-H., Jiang, W.-T., Li, Z., Kuo, C.-Y., Wu, Q., Jean, J. S., Lv, G. 2016. Interaction of ciprofloxacin and probe compounds with palygorskite PFL-1. J. Hazard. Mater. 303, 55-63. https://doi.org/10.1016/j.hazmat.2015.10.012

Chiari, G., Giustetto, R., Druzik, J., Doehne, E., Ricchiardi, G., 2008. Pre-columbian nanotechnology: Reconciling the mysteries of the maya blue pigment. Appl. Phys. A Mater. Sci. Process. 90, 3-7. https://doi.org/10.1007/s00339-007-4287-z

Chipera, S. J., Bish, D. L. 2001. Baseline studies of the Clay Minerals Society Source Clays: Powder X-ray diffraction analysis. Clays Clay Miner. 49, 398-409.

Dejoie, C., Martinetto, P., Dooryhée, E., Strobel, P., Blanc, S., Bordat, P., Brown, R., Porcher, F., Sanchez Del Rio, M., Anne, M., 2010. Indigo@silicalite: A new organic-inorganic hybrid pigment. ACS Appl. Mater. Interfaces 2, 2308-2316. https://doi.org/10.1021/am100349b 
Dogan, A. U., Dogan, M., Onal, M., Sarikaya, Aburub, A., Wurster, D. E. 2006. Baseline studies of the Clay Minerals Society Source Clays: Specific surface area by the Brunauer Emmett Teller (BET) method. Clays Clay Miner. 54, 62-66.

Doménech, A., Doménech-Carbó, M.T., Edwards, H.G.M., 2011. On the interpretation of the Raman spectra of Maya Blue: A review on the literature data. J. Raman Spectrosc. 42, 86-96. https://doi.org/10.1002/jrs.2642

Fan, L., Zhang, Y., Zhang, J., Wang, A., 2014. Facile preparation of stable palygorskite/cationic red X-GRL@SiO 2 "Maya Red” pigments. RSC Adv. 4, 63485-63493. https://doi.org/10.1039/C4RA13739F

Ferreira da Silva, P., Lima, J. C., Freitas, A. A., Shimizu, K., Maçanita, A. L., Quina, F. H., 2005. Charge-transfer complexation as a general phenomenon in the copigmentation of anthocyanins. J. Phys. Chem. A 109, 7329-7338. https://doi.org/10.1021/jp052106s

Ferreira, A. P. G., Frederice, R., Janssen, K. P. F., Gehlen, M. H., 2011. Dually fluorescent silica nanoparticles. J. Lumin. 131, 888-893. https://doi.org/10.1016/j.jlumin.2010.12.019

Freitas, A. A, Maçanita, A. A. L., Quina, F.H., 2013. Improved analysis of excited state proton transfer kinetics by the combination of standard and convolution methods. Photochem. Photobiol. Sci. 12, 902-10. https://doi.org/10.1039/c3pp25445c

Frini-Srasra, N., Srasra, E., 2008. Determination of Acid-Base Properties of HCl Acid Activated Palygorskite by Potentiometric Titration. Surf. Eng. Appl. Electrochem. 44, 401-409. https://doi.org/10.3103/S1068375508050116

Frost, R.L., Xi, Y., He, H., 2010. Synthesis, characterization of palygorskite supported zero-valent iron and its application for methylene blue adsorption. J. Colloid Interface Sci. 341, 153-161. https://doi.org/10.1016/j.jcis.2009.09.027 
Gago, S., Pessêgo, M., Laia, C.A.T., Parola, A.J., 2017. pH-Tunable Fluorescence and Photochromism of a Flavylium-Based MCM-41 Pigment. ACS Omega 2, 122-126. https://doi.org/10.1021/acsomega.6b00381

Gilchrist, A., Nobbs, J. 1999. Colorimetry, Theory. In Encyclopedia of Spectroscopy and Spectrometry, Second Ed. (2010), J. Lindon, G. Tranter, D. Koppenaal, Eds. Academic Press, NY; pp. 380-385.

Giustetto, R., Wahyudi, O., 2011. Sorption of red dyes on palygorskite: Synthesis and stability of red/purple Mayan nanocomposites. Microporous Mesoporous Mater. 142, 221-235. https://doi.org/10.1016/j.micromeso.2010.12.004

Giustetto, R., Llabrés I Xamena, F.X., Ricchiardi, G., Bordiga, S., Damin, A., Gobetto, R., Chierotti, M.R., 2005. Maya blue: A computational and spectroscopic study. J. Phys. Chem. B 109, 19360-19368. https://doi.org/10.1021/jp048587h

Giustetto, R., Levy, D., Wahyudi, O., Chiari, G., 2006. Crystal structure refinement of Maya Blue pigment prepared with deuterated indigo, using neutron powder diffraction. Eur. J. Mineral. 18, 629-640. https://doi.org/10.1127/09351221/2006/0018-0629

Giustetto, R., Levy, D., Wahyudi, O., Ricchiardi, G., Vitillo, J.G., 2011. Crystal structure refinement of a sepiolite/indigo Maya Blue pigment using molecular modelling and synchrotron diffraction. Eur. J. Mineral. 23, 449-466. https://doi.org/10.1127/0935$1221 / 2011 / 0023-2105$

Giustetto, R., Vitillo, J.G., Corazzari, I., Turci, F., 2014. Evolution and reversibility of host/guest interactions with temperature changes in a methyl red@palygorskite polyfunctional hybrid nanocomposite. J. Phys. Chem. C 118, 19322-19337. https://doi.org/10.1021/jp4091238

Guggenheim, S., Koster van Groos, A. F. 2001. Baseline studies of the Clay Minerals 
Society Source Clays: Thermal Analysis. Clays Clay Miner. 49, 433-443. https://doi.org/10.1346/CCMN.2001.0490507

Held, B., Tang, H., Natarajan, P., da Silva, C.P., Silva, V. O., Bohne, C., Quina, F.H., 2016. Cucurbit[7] uril inclusion complexation as a supramolecular strategy for color stabilization of anthocyanin model compounds. Photochem. Photobiol. Sci. 15, 752757. https://doi.org/10.1039/C6PP00060F

Hubbard, B., Kuang, W., Moser, A., Facey, G. A., Detellier, C. 2003. Structural study of Maya blue: textural, thermal and solid state multinuclear magnetic resonance characterization of the palygorskite-indigo and sepiolite-indigo adducts. Clays Clay Miner. 51, 318-326.

Kim, M. H., Choi, G., Elzatahry, A., Vinu, A. Choy, Y. B., Choy, J.-H., 2016. Review of clay-drug hybrid materials for biomedical applications: administration routes. Clays Clay Miner. 64, 115-130. https://doi.org/10.1346/CCMN.2016.0640204

Kohno, Y., Hoshino, R., Matsushima, R., Tomita, Y., Kobayashi, K., 2007. Stabilization of Flavylium Dyes by Incorporation in the Clay Interlayer. J. Jpn. Soc. Colour Mater. 80, 6-12. https://doi.org/https://doi.org/10.4011/shikizai1937.80.6

Kohno, Y., Shibata, Y., Oyaizu, N., Yoda, K., Shibata, M., Matsushima, R., 2008a. Stabilization of flavylium dye by incorporation into the pore of protonated zeolites. Microporous Mesoporous Mater. 114 $373-379$. https://doi.org/10.1016/j.micromeso.2008.01.023

Kohno, Y., Tsubota, S., Shibata, Y., Nozawa, K., Yoda, K., Shibata, M., Matsushima, R., 2008b. Enhancement of the photostability of flavylium dye adsorbed on mesoporous silicate. Microporous Mesoporous Mater. 116, 70-76. https://doi.org/10.1016/j.micromeso.2008.03.014

Kohno, Y., Kinoshita, R., Ikoma, S., Yoda, K., Shibata, M., Matsushima, R., Tomita, Y., 
649

650

651

652

653

654

655

656

657

658

659

660

661

662

663

664

665

666

667

668

669

670

671

672

673

Maeda, Y., Kobayashi, K., 2009. Stabilization of natural anthocyanin by intercalation into montmorillonite. Appl. Clay Sci. 42, 519-523. https://doi.org/10.1016/j.clay.2008.06.012

Kohno, Y., Hoshino, R., Ikoma, S., Shibata, M., Matsushima, R., Tomita, Y., Maeda, Y., Kobayashi, K., 2010. Stabilization of Flavylium Dye by Incorporation into Bentonite Clay. J. Jpn. Soc. Colour Mater. 83, 103-107. https://doi.org/https://doi.org/10.4011/shikizai.83.103

Kohno, Y., Senga, M., Shibata, M., Yoda, K., Matsushima, R., Tomita, Y., Maeda, Y., Kobayashi, K., 2011. Stabilization of flavylium dye by incorporation into Fecontaining mesoporous silicate. Microporous Mesoporous Mater. 141, 77-80. https://doi.org/10.1016/j.micromeso.2010.11.004

Kohno, Y., Kato, Y., Shibata, M., Fukuhara, C., Maeda, Y., Tomita, Y., Kobayashi, K., 2015. Enhanced stability of natural anthocyanin incorporated in Fe-containing mesoporous silica. Microporous Mesoporous Mater. 203, 232-237. https://doi.org/10.1016/j.micromeso.2014.10.042

Laguna, H., Loera, S., Ibarra, I.A., Lima, E., Vera, M.A., Lara, V., 2007. Azoic dyes hosted on hydrotalcite-like compounds: Non-toxic hybrid pigments. Microporous Mesoporous Mater. 98, 234-241. https://doi.org/10.1016/j.micromeso.2006.09.009

Lakowicz, J. R. 2006. Principles of Fluorescence Spectroscopy, $3^{\text {rd }}$ edition, Springer, New York; pp. 353-412.

Lauer, M.H., Gehlen, M.H., De Jesus, K., Berlinck, R.G.S., 2014. Fluorescence spectroscopy and confocal microscopy of the mycotoxin citrinin in condensed phase and hydrogel films. J. Fluoresc. 24, 745-750. https://doi.org/10.1007/s10895-013$1347-\mathrm{y}$

Li, Z., Willms, C. A., Kniola, K. 2003. Removal of anionic contaminants using surfactant- 
modified palygorskite and sepiolite. Clays Clay Miner., 51, 445-451.

Lima E, Martinez-Ortiz MJ, Fregoso E, Mendez-Vivar J. 2007. Capturing natural chromophores on natural and synthetic aluminosilicates. Stud. Surf. Sci. Catal. 170, 2110-2115. https://doi.org/10.1016/S0167-2991(07)81107-4

Lima, E., Guzmán, A., Vera, M., Rivera, J.L., Fraissard, J., 2012. Aged natural and synthetic Maya Blue-like pigments: What difference does it make? J. Phys. Chem. C 116, 4556-4563. https://doi.org/10.1021/jp207602m

Lima, J. C., Vautier-Giongo, C., Lopes, A., Melo, E., Quina, F. H., Maçanita, A. L. 2002. Color Stabilization of Anthocyanins: Effect of SDS Micelles on the Acid-Base and Hydration Kinetics of Malvidin 3-Glucoside (Oenin). J Phys. Chem. A, 106, 58515859. https://doi.org/10.1021/jp014081c

Lin, Y.H., Hori, Y., Hoshino, S., Miyazawa, C., Kohno, Y., Shibata, M., 2014. Fluorescent colored material made of clay mineral and phycoerythrin pigment derived from seaweed. Dye. Pigment. 100, 97-103. https://doi.org/10.1016/j.dyepig.2013.08.022

Lippens, B. C., de Boer, J. H. 1965. Studies on pore systems in catalysts: V. The $t$ method. J. Catal. 4, 319-323. https://doi.org/10.1016/0021-9517(65)90307-6

Madejová, J., Komadel, P. 2001. Baseline studies of the Clay Minerals Society Source Clays: Infrared methods. Clays Clay Miner. 49, 410-432.

Martínez-Martínez, V., Corcóstegui, C., Prieto, J. B., Gartzia, L., Sallares, S., Arbeloa, I. L. 2011. Distribution and orientation study of dyes intercalated into single sepiolite fibers. A confocal fluorescence microscopy approach. J. Mater. Chem. 21, 269-276. https://doi.org/10.1039/c0jm02211j

Mermut, A.R., Cano, A. F. 2001. Baseline studies of the Clay Minerals Society Source Clays: Chemical analyses of major elements. Clays Clay Miner. 49, 381-386. 
Mu, B., Wang, A., 2016. Adsorption of dyes onto palygorskite and its composites: A review. J. Environ. Chem. Eng. 4, 1274-1294. https://doi.org/10.1016/j.jece.2016.01.036

Ogawa, M., Takee, R., Okabe, Y., Seki, Y. 2017. Bio-geo hybrid pigment; clayanthocyanin complex which changes color depending on the atmosphere. Dyes Pigments, 139, 561-565. https://doi.org/10.1016/j.dyepig.2016.12.054

Quina, F.H., Moreira, P.F., Vautier-Giongo, C., Rettori, D., Rodrigues, R.F., Freitas, A.A., Silva, P.F., Macanita, A.L., 2009. Photochemistry of anthocyanins and their biological role in plant tissues. Pure Appl. Chem. 81, 1687-1694. https://doi.org/10.1351/Pac-Con-08-09-28

Ribeiro, H. L., Oliveira, A. V. D., Brito, E. S. D., Ribeiro, P. R. V., Souza Filho, M. D. S. M., Azeredo, H. M. C. 2018, Stabilizing effect of montmorillonite on acerola juice anthocyanins. Food Chem, 245 , 966-973. https://doi.org/10.1016/j.foodchem.2017.11.076

Ruiz-Hitzky, E. 2001. Molecular access to the intracrytalline tunnels of sepiolite. J. Mater. Chem. 11, 86-91. https://doi.org/10.1039/b003197f

Sánchez Del Río, M., Martinetto, P., 2006. Synthesis and Acid Resistance of Maya Blue Pigment. Archaeometry 48, 115-130. https://doi.org/10.1111/j.14754754.2006.00246.x

Sánchez Del Río, M., Boccaleri, E., Milanesio, M., Croce, G., Van Beek, W., Tsiantos, C., Chyssikos, G.D., Gionis, V., Kacandes, G.H., Suárez, M., García-Romero, E., 2009. A combined synchrotron powder diffraction and vibrational study of the thermal treatment of palygorskite-indigo to produce Maya blue. J. Mater. Sci. 44, 5524-5536. https://doi.org/10.1007/s10853-009-3772-5

Shariatmadari, H., Mermut, A. R., Benke, M. B. 1999. Sorption of selected cationic and 
neutral organic molecules on palygorskite and sepiolite. Clays Clay Miner. 47, 4453.

Silva, V.O., Freitas, A.A., Maçanita, A.L., Quina, F.H., 2016. Chemistry and photochemistry of natural plant pigments: the anthocyanins. J. Phys. Org. Chem. 29, 594-599. https://doi.org/10.1002/poc.3534

Silva, C. P., Pioli, R. M., Liu, L., Zheng, S., Zhang, M., Silva, G. T. de M., Carneiro, V. M. T., Quina, F. H., 2018. Improved Synthesis of Analogues of Red Wine Pyranoanthocyanin Pigments. ACS Omega 3, 954-960. https://doi.org/10.1021/acsomega.7b01955

Teixeira-Neto, Â.A., Shiguihara, A.L., Izumi, C.M.S., Bizeto, M.A., Leroux, F., Temperini, M.L.A., Constantino, V.R.L., 2009. A hybrid material assembled by anthocyanins from açaí fruit intercalated between niobium lamellar oxide. Dalt. Trans. 4136-4145. https://doi.org/10.1039/b820610d

Teixeira-Neto, Â.A., Izumi, C.M.S., Temperini, M.L.A., Ferreira, A.M.D.C., Constantino, V.R.L., 2012. Hybrid Materials Based on Smectite Clays and Nutraceutical Anthocyanins from the Açaí Fruit. Eur. J. Inorg. Chem. 2012, 54115420. https://doi.org/10.1002/ejic.201200702

Tilocca, A., Fois, E., 2009. The color and stability of maya blue: TDDFT calculations. J. Phys. Chem. C 113, 8683-8687. https://doi.org/10.1021/jp810945a

Tomasini, E.P., Román, E.S., Braslavsky, S.E., 2009. Validation of fluorescence quantum yields for light-scattering powdered samples by laser-induced optoacoustic spectroscopy. Langmuir 25, 5861-5868. https://doi.org/10.1021/la803492k

Ugochukwu, U. C., Jones, M. D., Head, I. M., Manning, D. A. C., Fialips, C. I. 2014. Biodegradation of crude oil saturated fraction supported on clays. Biodegradation 25, 153-165. https://doi.org/10.1007/s10532-013-9647-0 
Valandro, S.R., Poli, A.L., Neumann, M.G., Schmitt, C.C., 2015. Photophysics of auramine $\mathrm{O}$ adsorbed on solid clays. J. Lumin. 161, 209-213. https://doi.org/10.1016/j.jlumin.2015.01.023

Valandro, S.R., Poli, A.L., Correia, T.F.A., Lombardo, P.C., Schmitt, C.C., 2017. Photophysical Behavior of Isocyanine/Clay Hybrids in the Solid State. Langmuir 33, 891-899. https://doi.org/10.1021/acs.langmuir.6b03898

Yang, R., Li, D., Li, A., Yang, H. 2018. Adsorption properties and mechanisms of palygorskite for remocal of various ionic dyes from water. Appl. Clay Sci. 151, 2028. https://doi.org/10.1016/j.clay.2017.10.016

Zhang, H.T., Li, R., Yang, Z., Yin, C.-X., Gray, M.R., Bohne, C., 2014. Evaluating steady-state and time-resolved fluorescence as a tool to study the behavior of asphaltene in toluene. Photochem. Photobiol. Sci. 13, 917-928. https://doi.org/10.1039/c4pp00069b

Zhang, Y., Wang, W., Mu, B., Wang, Q., Wang, A., 2015a. Effect of grinding time on fabricating a stable methylene blue/palygorskite hybrid nanocomposite. Powder Technol. 280, 173-179. https://doi.org/10.1016/j.powtec.2015.04.046

Zhang, Y., Wang, W., Zhang, J., Liu, P., Wang, A., 2015b. A comparative study about adsorption of natural palygorskite for methylene blue. Chem. Eng. J. 262, 390-398. https://doi.org/10.1016/j.cej.2014.10.009

Zhang, Y., Fan, L., Chen, H., Zhang, J., Zhang, Y., Wang, A., 2015c. Learning from ancient Maya: Preparation of stable palygorskite/methylene blue@SiO2 Maya Bluelike pigment. Microporous Mesoporous Mater. 211, 124-133. https://doi.org/10.1016/j.micromeso.2015.03.002

Zhang, Y., Zhang, J., Wang, A., 2015d. Facile preparation of stable palygorskite/methyl violet@SiO2 “Maya Violet” pigment. J. Colloid Interface Sci. 457, 254-263. 
https://doi.org/10.1016/j.jcis.2015.07.030

775 Zhang, Y., Dong, J., Sun, H., Yu, B., Zhu, Z., Zhang, J., Wang, A., 2016a. Solvatochromic

Coatings with Self-Cleaning Property from Palygorskite@Polysiloxane/Crystal Violet Lactone. ACS Appl. Mater. Interfaces 8, 27346-27352. https://doi.org/10.1021/acsami.6b09252

Zhang, Y., Zhang, J., Wang, A., 2016b. From Maya blue to biomimetic pigments: durable 780 biomimetic pigments with self-cleaning property. J. Mater. Chem. A 4, 901-907. https://doi.org/10.1039/C5TA09300G 